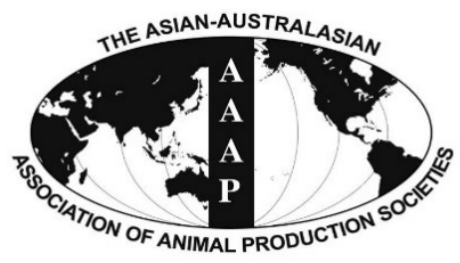

Open Access

Asian Australas. J. Anim. Sci.

Vol. 29, No. 11 : 1632-1638 November 2016

http://dx.doi.org/10.5713/ajas.15.0540

www.ajas.info

pISSN 1011-2367 elSSN 1976-5517

\title{
Methodologies for the Determination of Endogenous Phosphorus Losses in Growing Pigs
}

\author{
Débora Aline Alves ${ }^{1}$, Leonardo Tombesi da Rocha, Claudiele Aparecida dos Santos Camargo, \\ Andriele Medianeira Figueiredo, Marcos Speroni Ceron², Walter Lucca ${ }^{3}$, \\ Irineo Zanella, and Vladimir de Oliveira* \\ Department of Animal Science of the Federal University of Santa Maria, \\ Santa Maria, Rio Grande do Sul 97105-900, Brazil
}

\begin{abstract}
A study was conducted to compare the endogenous basal losses of phosphorus (EBLP) in pigs fed diets containing gelatin (GEL) or spray-dried porcine plasma (SDPP) as protein sources and to determine the standardized total tract digestibility (STTD) of phosphorus (P) in SDPP. The trial was carried out at the Federal University of Santa Maria, Brazil. Twelve castrated pigs with an initial body weight of $55 \mathrm{~kg}$ were individually allotted in metabolic crates during two 12-day periods, each with 7 days of adaptation and 5 days of total fecal collection. The beginning and the end of the collecting periods were determined according to the marker-to-marker approach, using ferric oxide as an indigestible marker. Pigs were submitted to four semi-purified diets, one being a P-free diet with 30\% of GEL as the protein source and three were diets with $10 \%, 20 \%$, and $30 \%$ inclusion of SDPP respectively. Data were subjected to analysis of variance and the model included the effects of period, animal and treatments; the results of the three diets with increased levels of SDPP were subjected to linear regression analysis. The intercept of the relation of between ingested P and absorbed P represented the EBLP, while the slope indicated the STTD of P in SDPP. The EBLP means obtained by P-free diet and regression method were compared with the Student $t$ test. The EBLP were $128.95 \mathrm{mg} / \mathrm{kg}$ dry matter intake $(\mathrm{DMI})$ and $153.63 \mathrm{mg} / \mathrm{kg}$ DMI (standard error $=77.0 ; \mathrm{p}<0.06$ ) using the P-free diet with GEL as the protein source and the regression method, obtained with diets containing increased levels of SDPP, respectively. The apparent digestibility of $\mathrm{P}$ was $87.9 \%, 94.2 \%$, and $92.9 \%$ for the treatments containing $10 \%, 20 \%$, and $30 \%$ inclusion of SDPP, respectively. The estimated STTD of P obtained with the linear regression was $97.4 \%$. When the EBLP estimated by the P-free diet was used to corrected the apparent digestibility of P in diets containing SDPP, the STTD of P in SDPP was 96.9\%, $98.8 \%$, and $95.9 \%$ for $10 \%, 20 \%$, and $30 \%$ SDPP, respectively. Therefore, it can be concluded that SDPP can replace GEL to estimate the endogenous losses of P. In addition, the STTD of P in SDPP estimated with the P-free diet was $97.2 \%$ and it was $97.4 \%$ by the regression method, utilizing SDPP. (Key Words: Digestibility, Gelatin, Phosphorus, Pigs, Protein Sources, Regression)
\end{abstract}

\section{INTRODUCTION}

The diets for pigs must contain optimal amounts of phosphorus $(\mathrm{P})$ to promote proper performance and avoid

\footnotetext{
* Corresponding Author: Vladimir de Oliveira. Tel: $+55-55-3220$ 8083, Fax: +55-55-96187157, E-mail: vladimir.oliveira@ufsm.br

${ }^{1}$ Federal University of Pelotas, Pelotas, RS 96160-000, Brazil.

2 Federal University of Rio Grande do Sul, Porto Alegre, RS 91501-970, Brazil.

${ }^{3}$ Federal Institute of Rio Grande do Sul, Sertão, RS 99170-000, Brazil.

Submitted Jun. 27, 2015; Revised Oct. 2, 2015; Accepted Jan. 12, 2016
}

excessive excretion resulting in an increased environmental impact of pig production. The amount of total P (PTOT) in most of the ingredients used in diets for pigs is variable, as is the ratio of PTOT for animals (Rostagno et al., 2011).

Availability is a way to express the P content in feedstuffs and is defined as the amount of $\mathrm{P}$ that is completely absorbed and utilized by the animal. Another measure used to express the $\mathrm{P}$ content in ingredients for pig diets is digestibility, which quantifies the digestive $\mathrm{P}$ disappearance.

The digestibility can be expressed as apparent, standardized or true. The apparent digestibility is calculated by the difference between the ingested $\mathrm{P}$ (PING) and $\mathrm{P}$ 
recovered in feces. To obtain standardized and true digestibility values of $P$, it is necessary to have an estimate of endogenous losses of $\mathrm{P}$, which comes from the salivary juice, gastric, biliary, pancreatic secretion and cell desquamation (Fan et al., 2001). In standardized digestibility, only the endogenous basal losses of phosphorus (EBLP) are considered (NRC, 2012), while in true digestibility, both basal and specific endogenous losses of $\mathrm{P}$ are considered.

The standardized digestibility is a good alternative to expressing the $\mathrm{P}$ content of feedstuffs for pigs, mainly because fecal endogenous losses of $\mathrm{P}$ are relatively easy to measure. Several methods are used to determine the endogenous $\mathrm{P}$, with the most common being the $\mathrm{P}$-free diet and the regression method. In the first case, the idea is to supply a P-free diet for pigs and quantify the $\mathrm{P}$ recovered in feces (Petersen and Stein, 2006; Almeida and Stein, 2012). On the other hand, in the regression method diets with increasing levels of $\mathrm{P}$ are provided to the animals and the EBLP are determined by the intercept of the relationship between absorbed P (PABS) and PING (Fan et al., 2001). In theory, the use of both P-free diet and the method of regression make it possible to obtain estimates of EBLP (Almeida and Stein, 2010).

The use of gelatin (GEL) as a protein source in P-free diets is recommended by authors who have studied this topic (Petersen and Stein, 2006). In Brazil, diets with low P content have been formulated with spray-dried porcine plasma (SDPP) as a protein source (Bünzen et al., 2012). Despite the low content and high digestibility of $\mathrm{P}$ present in the SDPP, its use can generate incorrect estimates of EBLP and, consequently, overestimate the standardized total tract digestibility (STTD) of $\mathrm{P}$ in pig feedstuff. One of the advantages of using the SDPP is the lower cost compared to GEL and the SDPP may be used as an alternative protein ingredient in P-free diets. However, no comparison of the endogenous losses with the GEL or SDPP as a protein source has been found in the literature.

Therefore, one study was conducted with the purpose of comparing the EBLP in pigs fed diets containing GEL or SDPP as a source of protein and determine the STTD of P in SDPP.

\section{MATERIALS AND METHODS}

\section{Experimental design, animals and diets}

The experiment was conducted in the Department of Animal Science of the Federal University of Santa Maria (UFSM); twelve castrated pigs from a commercial line with average weight of $55.0 \pm 2.5 \mathrm{~kg}$ were used. The animals were housed individually in metabolic cages equipped with feeders, drinkers and containers for the collection of feces and urine. The cages had variable widths and heights in order to adjust the area to the weight of the animal. The cages were kept in a room with a temperature range of $22^{\circ} \mathrm{C} \pm 3^{\circ} \mathrm{C}$ with the aid of an air conditioner.

The experimental period was divided in two consecutive phases with 12 days (seven days of adaptation to experimental conditions and five days for fecal collection). The animals were distributed through a balanced changeover design, with six replications. The treatments were four semipurified diets, one of which was free of $\mathrm{P}$ but had GEL as a protein source; the others contained $10 \%, 20 \%$, or $30 \%$ of SDPP as the protein source (Table 1). The diets with the addition of SDPP were isocaloric and the ratio of calcium (Ca) and $\mathrm{P}(\mathrm{Ca}: \mathrm{P})$ in all treatments was $1: 1.5$; the remainder of the minerals and vitamins were included to meet or exceed the recommendations of Rostagno et al. (2011).

The animals received four meals (8:00, 11:30, 14:00, and $17: 30 \mathrm{~h}$ ), in the amount of $75 \mathrm{~g} / \mathrm{kg} \mathrm{BW}^{0.75}$ per day. Daily feed refusals were collected, dried, weighed and discounted from the total amount provided.

Table 1. Ingredients and chemical composition as feed basis of semi-purified diets with different spray-dried porcine plasma (SDPP) levels and phosphorus-free diet

\begin{tabular}{|c|c|c|c|c|}
\hline \multirow[t]{2}{*}{ Items } & \multirow{2}{*}{$\begin{array}{c}\text { P-free } \\
\text { diet }\end{array}$} & \multicolumn{3}{|c|}{$\begin{array}{c}\text { Spray-dried porcine } \\
\text { plasma }(\%)\end{array}$} \\
\hline & & 10 & 20 & 30 \\
\hline \multicolumn{5}{|l|}{ Ingredient (\%) } \\
\hline Gelatin & 30.00 & - & - & - \\
\hline SDPP & - & 10.00 & 20.00 & 30.00 \\
\hline Starch & 37.25 & 61.15 & 50.51 & 39.90 \\
\hline Sugar & 20.00 & 20.00 & 20.00 & 20.00 \\
\hline Salt & 0.40 & - & - & - \\
\hline Soya oil & 6.00 & 3.00 & 3.00 & 3.00 \\
\hline Cellulose & 4.20 & 4.20 & 4.20 & 4.20 \\
\hline Limestone & 0.20 & 0.50 & 1.00 & 1.50 \\
\hline L-threonine & 0.30 & 0.03 & 0.05 & 0.05 \\
\hline DL-methionine & 0.45 & 0.10 & 0.20 & 0.30 \\
\hline L-tryptophan & 0.20 & 0.02 & 0.04 & 0.05 \\
\hline Vitamin/mineral premix ${ }^{1}$ & 1.00 & 1.00 & 1.00 & 1.00 \\
\hline $\operatorname{ME}(\mathrm{kcal} / \mathrm{kg})^{3}$ & 3,215 & 3,504 & 3,510 & 3,516 \\
\hline Crude protein $(\%)^{3}$ & 28.20 & 7.20 & 14.50 & 21.70 \\
\hline Dry matter $(\%)^{2}$ & 90.83 & 89.99 & 90.34 & 90.59 \\
\hline Mineral matter $(\%)^{2}$ & 0.80 & 1.40 & 2.48 & 3.48 \\
\hline $\operatorname{NDF}(\%)^{3}$ & 3.80 & 3.80 & 3.80 & 3.80 \\
\hline Calcium $(\%)^{3}$ & 0.09 & 0.21 & 0.43 & 0.64 \\
\hline Total phosphorus $(\%)^{2}$ & 0.01 & 0.14 & 0.29 & 0.43 \\
\hline $\mathrm{Ca}: \mathrm{P}(\%)^{3}$ & - & $1: 1.5$ & $1: 1.5$ & $1: 1.5$ \\
\hline
\end{tabular}

ME, metabolizable energy; NDF, neutral detergent fiber; $\mathrm{Ca}$, calcium.

${ }^{1}$ Amount $/ \mathrm{kg}$ of vitamin and mineral premix: vitamin A 1,750,000 UI; vitamin $\mathrm{D}_{3} 300,000 \mathrm{UI}$; vitamin E 10,000 mg; vitamin $\mathrm{K}_{3} 400 \mathrm{mg}$; vitamin $\mathrm{B}_{1} 250 \mathrm{mg}$; vitamin $\mathrm{B}_{2} 750 \mathrm{mg}$; vitamin $\mathrm{B}_{6} 250 \mathrm{mg}$; vitamin $\mathrm{B}_{12} 3,000 \mathrm{mg}$; niacin 5,000 mg, Pantothenic Ac. 3,000 mg; choline, 3,000 mg; antioxidant 5,000 mg; Fe, 8,000 mg as iron sulfate; $\mathrm{Cu}, 1,200 \mathrm{mg}$ as copper sulfate; Mn, 7,000 mg as manganese sulfate; $\mathrm{Zn}, 10,000 \mathrm{mg}$ as zinc oxide. ${ }^{2}$ Analyzed values.

${ }^{3}$ Calculated values according Rostagno et al. (2011), except gelatin (NRC, 1998), and amino acids (Sauvant, 2006). 


\section{Data and sample: collections and analysis}

The feces were collected according to the marker-tomarker approach using ferric oxide $(1 \%)$ as a marker. Feces were collected twice daily (Adeola, 2001), placed in plastic bags and kept in a freezer at $-18^{\circ} \mathrm{C}$. At the end of each period, the feces were thawed and homogenized, and an aliquot was removed for drying at $65^{\circ} \mathrm{C}$ in a forced air oven, before being milled for chemical analysis. The analyses of dry matter (DM, method 930.15), mineral matter (MM, method 942.05) and $P$ (method 946.06) were performed according to AOAC (2005). $P$ concentration in feed and fecal samples was determined by gravimetric procedures after wet ashing.

The EBLP derived from diets with inclusion of SDPP was obtained by the regression method with the value of the intercept (Y) of the linear relationship between the PABS and PING, while the STTD of P in SDPP was obtained from the slope of the relationship mentioned previously (Fan et al., 2001). For the method of P-free diet, the entire $P$ recovered in the feces of pigs receiving a P-free diet was considered EBLP (Petersen and Stein, 2006).

\section{Statistical analysis}

The data were subjected to analysis of variance, using in the model fixed effects of animal, treatment and period. Means comparison was performed using the Tukey test for contrast between protein sources $(\mathrm{GEL} \times \mathrm{SDPP})$ and within SDPP diets. Endogenous loss estimates were compared by the Student T test and the relations between PING and PABS were studied by linear regression procedures. The experimental unit was a pig. An alpha level below of 0.05 was considered as statistically significant and values of alpha above 0.05 or below then 0.10 were considered tendency. All statistical analyses were performed using the statistical program MINITAB (2013).

\section{RESULTS AND DISCUSSION}

The animals remained healthy during the experimental period and feces samples were obtained without any problem.

The GEL used to formulate the P-free diet showed 0.03\% PTOT and was supplemented with DL-methionine, Lthreonine, and L-tryptophan to improve the quality of its protein (Table 1). The SDPP (AP 920) used in this study contained $1.4 \%$ total $\mathrm{P}$.

The dry matter intake (DMI) was different between the treatments $(\mathrm{p}<0.01$; Table 2$)$. The animals eating P-free diets, with GEL as a protein source, had DMI that was $18.5 \%$ lower $(\mathrm{p}<0.01)$ than animals fed diets with the inclusion of SDPP $(1,128.6$ vs. $1,382.4 \mathrm{~g} / \mathrm{d}$, respectively). It is possible that the lower intake observed in animals fed diets with GEL occurred due to the reduced palatability of this ingredient. However, in other experiments determining endogenous $\mathrm{P}$ with GEL as a protein source in a P-free diet, no problem with feed intake was observed (Kim et al., 2012; Rojas and Stein, 2012; Baker et al., 2013).

The comparison between treatments with SDPP showed an intake that was $15 \%$ higher $(\mathrm{p}<0.01)$ in pigs ingesting diets with $20 \%$ of the ingredient tested and equality between the levels of $10 \%$ and $30 \%$. At present, no explanations exist for the higher intake of pigs fed diets with intermediate levels

Table 2. Apparent total tract digestibility of dry matter, mineral matter and phosphorus balance in growing pigs fed with P-free diet and the technique of simple regression

\begin{tabular}{|c|c|c|c|c|c|c|c|c|}
\hline \multirow{2}{*}{ Variables } & \multirow{2}{*}{ Gelatin } & \multicolumn{3}{|c|}{ Spray-dried porcine plasma (\%) } & \multirow{2}{*}{ MSE } & \multicolumn{3}{|c|}{ Probability } \\
\hline & & 10 & 20 & 30 & & Animal & Diet & Period \\
\hline$\overline{\mathrm{N}}$ & 6 & 6 & 6 & 6 & - & - & - & - \\
\hline Live weight $(\mathrm{kg})$ & 54.87 & 58.32 & 61.21 & 60.10 & - & - & - & - \\
\hline Diet intake $(\mathrm{g} / \mathrm{d})^{1}$ & $1,242.34$ & $1,450.94^{y}$ & $1,670.94^{x}$ & $1,470.60^{\mathrm{y}}$ & 54.10 & $<0.01$ & $>0.05$ & $<0.01$ \\
\hline Recovered feces $(\mathrm{g} / \mathrm{d})^{1}$ & 477.20 & $939.20^{y}$ & $896.20^{y}$ & $1180.20^{\mathrm{x}}$ & 84.80 & $>0.05$ & $<0.01$ & $<0.01$ \\
\hline$D M$ in feces $(g / d)^{1}$ & 51.32 & $83.81^{\mathrm{x}}$ & $90.88^{\mathrm{x}}$ & $101.25^{\mathrm{x}}$ & 5.82 & $>0.05$ & $<0.05$ & $>0.05$ \\
\hline DM absorbed $(\mathrm{g} / \mathrm{d})^{1}$ & $1,077.30$ & $1,222.00^{\mathrm{x}}$ & $1,418.50^{\mathrm{y}}$ & $1,230.70^{\mathrm{x}}$ & 97.93 & $<0.05$ & $<0.05$ & $<0.05$ \\
\hline ATTD of DM $(\%)^{1}$ & 95.48 & $93.65^{x}$ & $93.83^{\mathrm{x}}$ & $92.12^{\mathrm{x}}$ & 0.64 & $>0.05$ & $<0.05$ & $>0.05$ \\
\hline MM intake $(\mathrm{g} / \mathrm{d})^{1}$ & 93.20 & $210.50^{z}$ & $349.70^{y}$ & $446.10^{x}$ & 18.20 & $>0.05$ & $<0.01$ & $<0.01$ \\
\hline MM in feces $(g / d)^{1}$ & 5.94 & $6.71^{\mathrm{z}}$ & $9.56^{\mathrm{y}}$ & $11.46^{\mathrm{x}}$ & 1.19 & $>0.05$ & $<0.01$ & $>0.05$ \\
\hline MM absorbed $(\mathrm{g} / \mathrm{d})^{1}$ & 87.20 & $203.80^{z}$ & $340.10^{y}$ & $434.60^{\mathrm{x}}$ & 33.00 & $>0.05$ & $<0.05$ & $<0.05$ \\
\hline ATTD of MM $(\%)^{1}$ & 93.67 & $95.80^{\mathrm{z}}$ & $97.10^{\mathrm{x}}$ & $97.35^{\mathrm{x}}$ & 0.64 & $>0.05$ & $<0.05$ & $<0.01$ \\
\hline$P$ intake $(g / d)^{1}$ & 0.02 & $2.15^{z}$ & $4.11^{\mathrm{y}}$ & $5.50^{\mathrm{x}}$ & 0.31 & $>0.05$ & $<0.01$ & $<0.05$ \\
\hline P in feces $(g / d)^{1}$ & 0.16 & $0.26^{\mathrm{y}}$ & $0.24^{y}$ & $0.39^{\mathrm{x}}$ & 0.03 & $>0.05$ & $<0.01$ & $<0.01$ \\
\hline P absorbed $(\mathrm{g} / \mathrm{d})^{1}$ & -0.14 & $1.89^{\mathrm{z}}$ & $3.87^{y}$ & $5.11^{\mathrm{x}}$ & 0.32 & $>0.05$ & $<0.01$ & $<0.05$ \\
\hline ATTD of P (\%) & - & $87.90^{\mathrm{z}}$ & $94.16^{\mathrm{x}}$ & $92.91^{\mathrm{x}}$ & 0.52 & $>0.05$ & $<0.05$ & $<0.01$ \\
\hline
\end{tabular}

MSE, mean standard error; P, phosphorus; N, number of replications per treatment; DM, dry matter; ATTD, apparent total tract digestibility; MM, mineral matter; GEL, gelatin; SDPP, spray-dried porcine plasma.

${ }^{a}$ Difference due to protein source $(\mathrm{GEL} \times \mathrm{SDPP})(\mathrm{p}<0.05)$.

$\mathrm{x}, \mathrm{y}, \mathrm{z}$ Means of SDPP without common letter were significant $(\mathrm{p}<0.05)$. 


\section{of SDPP.}

The apparent total tract digestibility (ATTD) of DM was higher in the diet using GEL $(\mathrm{p}<0.05)$ compared with SDPP diets $(95.5 \%$ and $93.2 \%$, respectively). It is believed that these results were due to differences in the digestibility of dry matter between GEL and SDPP. On the other hand, the comparison between diets containing SDPP indicated no differences $(p>0.05)$ between inclusion levels of SDPP.

There were differences $(p<0.01)$ in the $M M$ intake between GEL and SDPP treatments. These results reflect the amount of MM present in GEL and SDPP $(1.45 \%$ and $7.74 \%$, respectively). However, the inverse occurred with the ATTD of MM, where the GEL diet provided an ATTD of MM that was around 3 percentage points lower $(p<0.01)$ than the diet with SDPP.

The diets with SDPP provided a $\mathrm{P}$ intake that was greater than that of the GEL diet, which was expected because GEL is virtually free of P. In the treatments with SDPP, there was a linear increase in PING with a higher SDPP level in the diet. The linearity in the relationship between the intake and excretion of $\mathrm{P}$ is one of the assumptions for validating the conclusions when using the regression method (Fan et al., 2001; Stein et al., 2007).

The EBLP measured in pigs receiving the P-free diet was $128.95 \mathrm{mg} / \mathrm{kg} \mathrm{DMI}$; this value is about $8 \%$ lower than that found by Petersen and Stein (2006) using diets containing 30\% GEL and pigs with an average weight of $53.1 \mathrm{~kg}$. Sulabo and Stein (2013) obtained values that were $21 \%$ lower in one study including $20 \%$ GEL in the diet tested and using pigs with an average weight of $18 \mathrm{~kg}$. When considering the number of considered studies, it was verified that the endogenous losses from P-free diets containing GEL as a source of protein had an average of 166.3 and standard deviation $35.8 \mathrm{mg} / \mathrm{kg}$ DMI (Petersen and Stein, 2006; Almeida and Stein, 2010; Almeida and Stein, 2012; Kim et al., 2012; Rojas and Stein, 2012; Baker et al., 2013; Sulabo and Stein, 2013). Thus, we realized that the estimated values in this study approached from average values reported in the literature.

The results of endogenous losses and standardized digestibility of P in diets with SDPP were calculated by the technique of simple linear regression, using the methodology described by Fan et al. (2001). The relationship between PABS and PING indicated an intercept of $153 \mathrm{mg} / \mathrm{kg}$ DMI (standard error $[\mathrm{SE}]=77.0, \mathrm{p}<0.06$ ) as an estimate of the EBLP in feces (Figure 1). For the analysis of data from the literature, it can be seen that EBLP estimated by the regression method are quite variable. In experiments with soybean meal as a source of $P$, for example, average values of $505 \mathrm{mg} / \mathrm{kg}$ DMI from EBLP have been found with a standard deviation of $270 \mathrm{mg} / \mathrm{kg}$ DMI (Fan et al., 2001; Ajakaiye et al., 2003; Zou et al., 2007a,b; Zhang et al., 2008; Akinmusire and Adeola, 2009). Differences in experimental conditions such as basal diet, housing, and animal genetics can determine these differences. Obviously, the good estimates of EBLP are important for feed evaluation, such as the maintenance requirements of $P$ (Yang et al., 2007).

The fecal content of $\mathrm{P}$ is due to unabsorbed $\mathrm{P}$ originating in the diet consumed by the animal and also the endogenous P. Endogenous losses, in turn, can be decomposed into basal or non-specific, and extra or specific, with the EBLP being attributed exclusively to the dry matter intake, and the latter being related to the composition of the test food (Mosenthin et al., 2000). In theory, it is expected that the regression method results estimate the EBLP similar to that obtained with a P-free diet, because the composition of the basal diet was similar for both methods.

The aim of this study was to determine whether the EBLP with the method of regression, using the SDPP as a protein source, would be compatible with the basal losses estimated using P-free diets. The comparison between the endogenous losses shows that there was no difference $(p>0.05)$ when it was obtained by the P-free method, with GEL as a protein source, or by the regression method. We emphasize, however,

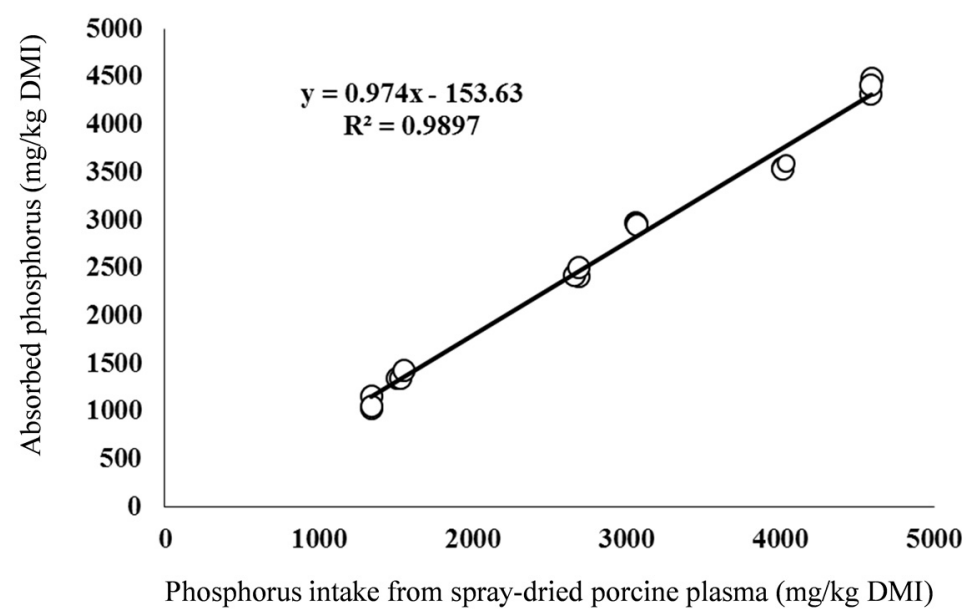

Figure 1. Relationship between absorbed phosphorus ( $\mathrm{mg} / \mathrm{kg}$ dry matter intake, DMI) and ingested phosphorus $\mathrm{mg} / \mathrm{kg} \mathrm{DMI}$ in diets with spray-dried porcine plasma with six observations per treatment. 


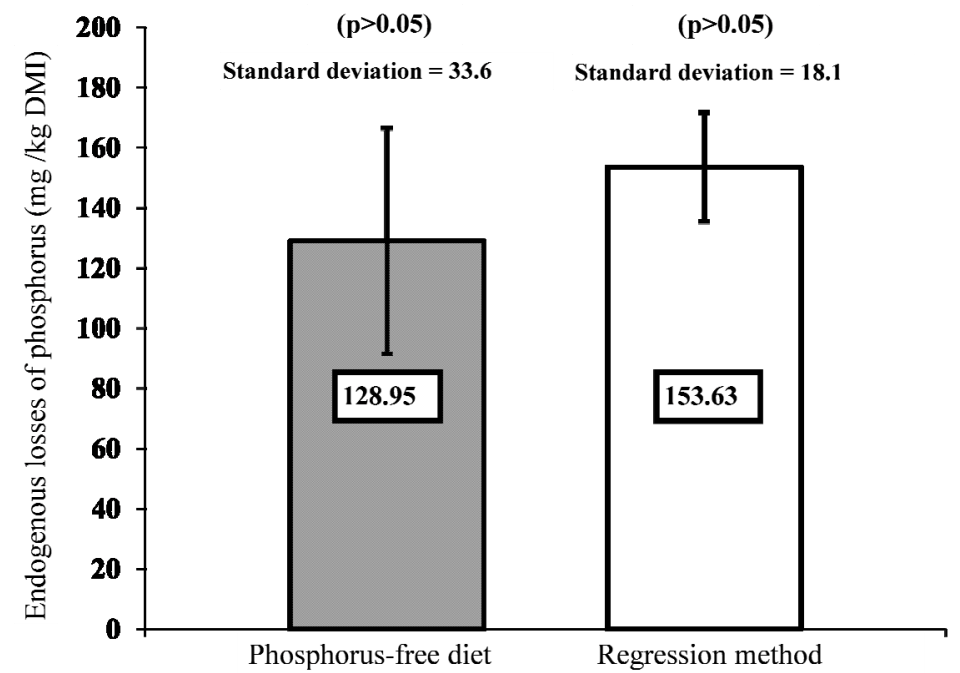

Figure 2. Estimated values of endogenous phosphorus losses $\mathrm{mg} / \mathrm{kg}$ dry matter intake (DMI) from phosphorus free diet or the regression method with six observations per treatment.

that the P-free diet induced a loss that was approximately $18 \%$ lower than the regression method (Figure 2).

Therefore, it is suggested that the SDPP can serve as a source of amino acids in diets designed to estimate the EBLP. However, it must be considered that the digestibility of $\mathrm{P}$ in SDPP is high, but not $100 \%$, which leads to the need to consider the indigestible fraction in the calculations of endogenous losses.

Pigs with a body weight of $60 \mathrm{~kg}$ should ingest $6.4 \mathrm{~g}$ of digestible P (PDIG) a day (Rostagno et al., 2011). Considering a daily consumption of $2.3 \mathrm{~kg} \mathrm{DM}$ and associating that consumption with our EBLP estimates, this implies that EBLP lost in the feces represent 7\% of PDIG required by pigs (Rostagno et al., 2011). This value is $25 \%$ higher than that reported by Shen et al. (2002), which may be justified because the authors have obtained EBLP that are 4 times higher than the average value obtained in this experiment.
The comparison between the apparent digestibility values of $\mathrm{P}$, with the standardized digestibility values of $\mathrm{P}$ (97.4\%) obtained from the simple regression technique, is shown in Figure 3. The apparent digestibility of $\mathrm{P}$ was $87.9 \%$, $94.2 \%$, and $92.9 \%$ for treatments with $10 \%, 20 \%$, and $30 \%$ of SDPP inclusion, respectively. Apparent digestibility values increase in response to the higher consumption of $\mathrm{P}$ because the endogenous losses, when expressed as a percentage of total $\mathrm{P}$ recovered in the feces, decrease proportionately (Mosenthin et al., 2000; Stein et al., 2007). The estimated standardized digestibility of $\mathrm{P}$ (97.4\%) generated by simple linear regression technique corrected the values for endogenous basal flux of $\mathrm{P}$, which remain unchanged, independent of the P inclusion level (Yang et al., 2007).

The standardized digestibility value of $\mathrm{P}$ in the SDPP found in our experiment was 5 percentage points higher than that cited by Rostagno et al. (2011), but close to the value of

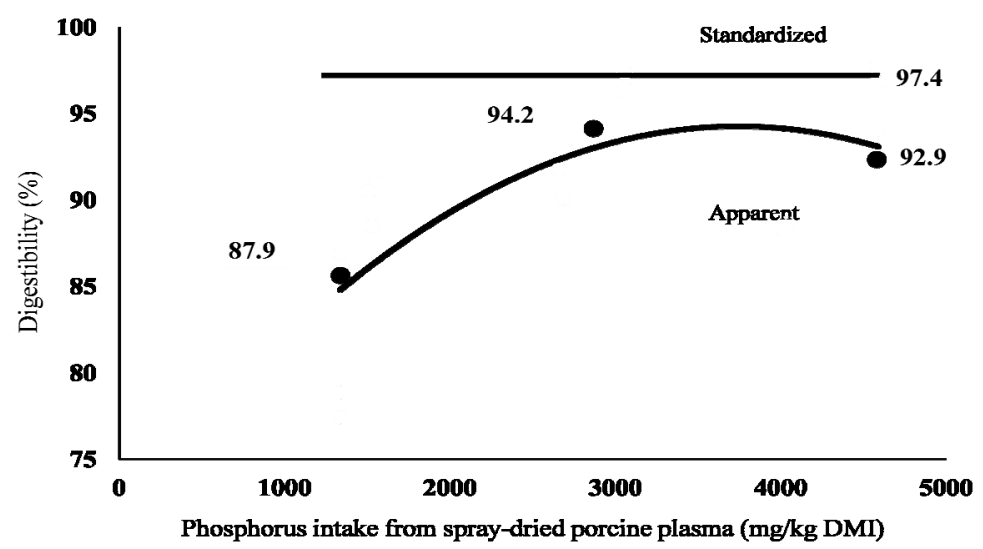

Figure 3. Effect of ingested phosphorus $\mathrm{mg} / \mathrm{kg}$ dry matter intake (DMI) in standardized and apparent digestibility with spray-dried porcine plasma with six observations per treatment. 
$98 \%$ of standardized digestibility presented in the NRC (2012). This result demonstrates that the P in SDPP has high digestibility that is associated with low content, meaning that it can be recommended as a substitute for GEL in P-free diet.

The apparent digestibility values of $\mathrm{P}$ obtained at different levels of inclusion of SDPP were corrected according to the equation suggested by Mosenthin et al. (2000): STTD of P in SDPP $(\%)=\operatorname{ATTD}(\%)+[($ EBLP $\mathrm{mg} / \mathrm{kg}$ $\mathrm{DMI} \div \mathrm{P}$ content in the diet $\mathrm{mg} / \mathrm{kg} \mathrm{DM}) \times 100$ ] by the basal diet loss obtained by the method of P-free diet, with GEL as a protein source; here, the values of $96.9 \%, 98.7 \%$, and $95.9 \%$ (data are not shown) were found for the standard $\mathrm{P}$ digestibility for contents of $10 \%, 20 \%$, and $30 \%$ inclusion of SDPP, respectively, and an average value of $97.2 \%$.

Stein et al. (2007) recommend that the basal amino acid flux be measured routinely in studies aiming to evaluate ileal digestibility. The suggestion comes from the observation that even with standardized experimental conditions and analytical procedures, discrepancies are detected. This same recommendation can be extended to studies whose purpose is to determine the EBLP.

\section{CONCLUSION}

SDPP can replace GEL as a protein source in P-free diets designed to determine endogenous losses of P. The EBLP showed an inevitable minimal loss of $\mathrm{P}$ for pigs of 141.3 $\mathrm{mg} / \mathrm{kg}$ DM intake. The STTD of P in the SDPP was 97.2\%, as estimated by P-free diet and $97.4 \%$ using SDPP as a protein source.

\section{CONFLICT OF INTEREST}

We certify that there is no conflict of interest with any financial organization regarding the material discussed in the manuscript.

\section{ACKNOWLEDGMENTS}

The authors gratefully acknowledge the Animal Science Department of Federal University of Santa Maria for the financial support.

\section{REFERENCES}

Adeola, O. 2001. Digestion and balance techniques in pigs. In: Swine Nutrition (Eds. A. J. Lewis and L. L. Southern). CRC Press, Washington, DC, USA. pp. 903-916.

Ajakaiye, A., M. Z. Fan, T. Archbold, R. R. Hacker, C. W. Forsberg, and J. P. Phillips. 2003. Determination of true digestive utilization of phosphorus and the endogenous phosphorus outputs associated with soybean meal for growing pigs. J. Anim. Sci. 81:2766-2775.

Akinmusire, A. S. and O. Adeola. 2009. True digestibility of phosphorus in canola and soybean meals for growing pigs:
Influence of microbial phytase. J. Anim. Sci. 87:977-983.

Almeida, F. N. and H. H. Stein. 2010. Performance and phosphorus balance of pigs fed diets formulated on the basis of values for standardized total tract digestibility of phosphorus. J. Anim. Sci. 88:2968-2977.

Almeida, F. N. and H. H. Stein. 2012. Effects of graded levels of microbial phytase on the standardized total tract digestibility of phosphorus in corn and corn coproducts fed to pigs. J. Anim. Sci. 90:1262-1269.

AOAC (Association of Official Analytical Chemists). 2005. Official Methods of Analysis. 18th edn. Association of Official Analytical Chemists, Arlington, VA, USA.

Baker, S. R., B. G. Kim, and H. H. Stein. 2013. Comparison of values for standardized total tract digestibility and relative bioavailability of phosphorus in dicalcium phosphate and distillers dried grains with solubles fed to growing pigs. J. Anim. Sci. 91:203-210.

Bünzen, S., H. S. Rostagno, C. Kiefer, A. T. Oliveira, and V. R. Junior. 2012. Digestible phosphorus levels for growing swine. Rev. Bras. Zootec. 41:320-325.

Fan, M. Z., T. Archbold, W. C. Sauer, D. Lackeyram, T. Rideout, Y. Gao, C. F. M. de Lange, and R. R. Hacker. 2001. Novel methodology allows simultaneous measurement of true phosphorus digestibility and the gastrointestinal endogenous phosphorus outputs in studies with pigs. J. Nutr. 131:2388-2396.

Kim, B. G., J. W. Lee, and H. H. Stein. 2012. Energy concentration and phosphorus digestibility in whey powder, whey permeate, and low-ash whey permeate fed to weanling pigs. J. Anim. Sci. 90:289-295.

MSS (Minitab Statistical Software). 2013. Release 16.1 for windows. Minitab Inc. State College PA, USA.

Mosenthin, R., W. C. Sauer, R. Blank, J. Huisman, and M. Z. Fan. 2000. The concept of digestible amino acids in diet formulation for pigs. Livest. Prod. Sci. 64:265-280.

NRC (National Research Council). 1998. Nutrient Requirements of Swine. 10th rev. edn. National Academy Press, Washington, DC, USA.

NRC (National Research Council). 2012. Nutrient Requirements of Swine. 12th edn. National Academy Press, Washington, DC, USA.

Petersen, G. I. and H. H. Stein. 2006. Novel procedure for estimating endogenous losses and measurement of apparent and true digestibility of phosphorus by growing pigs. J. Anim. Sci. 84:2126-2132.

Rojas, O. J. and H. H. Stein. 2012. Digestibility of phosphorus by growing pigs of fermented and conventional soybean meal without and with microbial phytase. J. Anim. Sci. 90:1506-1512.

Rostagno, H. S., L. F. T. Albino, J. L. Donzele, P. C. Gomes, R. F. Oliveira, D. C. Lopes, A. S. Ferreira, and S. L. Toledo Barreto. 2011. Brazilian Tables for Poultry and Swine: Composition of Feedstuffs and Nutritional Requirements. 3rd edn. Departamento de Zootecnia UFV, Viçosa, MG, Brasil.

Sauvant D., J. M. Perez, and G. Tran. 2004. Tables of composition and nutritional value of feed materials: Pigs, poultry, cattle, sheep, goats, rabbits, horses, and fish. 2nd edn. Wageningen Academic Publishers, Wageningen, the Netherlands. INRA ed. Paris, France.

Shen, Y., M. Z. Fan, A. Ajakaiye, and T. Archbold. 2002. Use of the regression analysis technique to determine the true phosphorus digestibility and the endogenous phosphorus output associated 
with corn in growing pigs. J. Nutr. 132:1199-1206.

Stein, H. H., B. Sève, M. F. Fuller, P. J. Moughan, C. F. M. de Lange, and Committee on Terminology to Report AA Bioavailability and Digestibility. 2007. Invited review: Amino acid bioavailability and digestibility in pig feed ingredients: Terminology and application. J. Anim. Sci. 85:172-180.

Sulabo, R. C. and H. H. Stein. 2013. Digestibility of phosphorus and calcium in meat and bone meal fed to growing pigs. J. Anim. Sci. 91:1285-1294

Yang, H., A. K. Li, Y. L. Yin, T. J. Li, Z. R. Wang, G. Wu, R. L. Huang, X. F. Kong, C. B. Yang, and P. Kang, et al. 2007. True phosphorus digestibility and the endogenous phosphorus outputs associated with brown rice for weanling pigs measured by the simple linear regression analysis technique. Animal $1: 213-220$.
Zhang, T. Y., Y. L. Zhang, S. M. Yan, Y. L. Yin, M. Z. Fan, and J. Wang. 2008. Study on the determination of endogenous outputs and true digestibility of calcium and phosphorus with soybean meal for growing pigs by linear regression analysis technique. Xu Mu Shou Yi Xue Bao 39:1684-1691.

Zuo, J. J., J. Wang, T. Y. Zhang, D. Y. Feng, Y. L. Yin, and M. Z. Fan. 2007a. Study on Endogenous outputs and true digestibility of phosphorus with sorghum and soybean meal in growing pigs by multiple linear regression analysis technique. Chinese J. Anim. Nutr. 19:91-98.

Zuo, J. J., J. Wang, T. Y. Zhang, C. M. Zhang, D. Y. Feng, Y. L. Yin, and M. Z. Fan. 2007b. Endogenous outputs and true digestibility of phosphorus associated with peanut meal and soybean meal in growing pigs by multiple linear regression analysis technique. Xu Mu Shou Yi Xue Bao 38:678-684. 